International Journal of

Emerging Multidisciplinary Research

\title{
Cultivation of Maker Teachers Under Coordinated Development
}

\author{
Weisong Liu ${ }^{1}$, Shimei Jin ${ }^{1}$ and Yongzhen $\mathrm{Li}^{2}$ \\ ${ }^{1}$ Department of Educational Technology, Yanbian University, Yanji, 133002, China \\ ${ }^{2}$ Department of Computer Science \& Technology, Yanbian University, Yanji, 133002, China
}

\begin{abstract}
Background/Objectives: This paper aims to improve the teaching quality of maker teachers in China by constructing the training mode of maker teachers under the concept of coordinated development of local universities and basic education in the context of the new era. Methods/Statistical analysis: In order to better implement the training model of maker teachers in this study, this paper designs a maker laboratory. Findings: From the perspective of normal students in Colleges and universities, the training model of maker teachers under the concept of coordinated development of local colleges and basic education constructed in this paper can make up for the shortcomings existing in the previous training model of teachers, not only provide full internship opportunities for normal students, but also provide them with teaching guidance, so that normal students can fully integrate theory and practice and improve their own teaching level. Improvements/Applications: Not only more high-quality maker teachers for basic education, but also better promote the development of maker education.
\end{abstract}

\section{Index Terms}

Basic education, Coordinated development, Local colleges and universities, Maker teachers

\author{
Corresponding author : Yongzhen Li \\ 1yz2008@ybu.edu.cn \\ - Manuscript received October 7, 2019. \\ - Revised October 30, 2019 ; Accepted November 12, 2019. \\ - Date of publication December 31, 2019. \\ (C) The Academic Society of Convergence Science Inc. \\ 2546-1583 @ 2017 IJEMR. Personal use is permitted, but republication/redistribution requires IJEMR permission.
}




\section{INTRODUCTION}

In 2013, President Obama of the United States mentioned that innovative manufacturing industry will be the future development goal of the United States. In the United States, 1000 maker spaces will be set up to carry out maker education activities and allocate $\$ 10$ million[1]. Since then, many colleges and universities in the United States have joined in the team of campus maker space construction, and the team has grown stronger and stronger[2]. Under the background of "mass entrepreneurship and innovation", the state attaches more and more importance to the cultivation of innovative talents. Maker education aims to cultivate students' practical ability and innovation ability. If it can give full play to its due effect, which can provide a large number of innovative talents for the country. However, the maker education in our country is still in the primary stage, there are some problems, such as: the lack of teachers, curriculum resources, teaching evaluation system is not perfect[3]. Maker teachers are the main driving force for the development and popularization of maker Education. The reason why the maker education is still in the bottleneck period is largely due to the lack of teachers. At present, most of the teachers engaged in maker education are information technology teachers and science teachers. Although they are sensitive to advanced technology, they still need to learn and update their theoretical knowledge[4]. It is urgent to build a trinity of maker teacher training system(college tutor, basic education tutor, normal school students) to better promote the development of maker education under the background of the new era. In the current environment, this paper tries to promote the deep cooperation between local universities and primary schools and improve the quality of maker teachers. To some extent, it can provide more high-quality maker teachers for primary and secondary schools and promote maker education.

\section{CONCEPT DEFINITION}

\section{A. Maker teachers}

As the key force to promote the development of maker education,maker teachers with education and teaching theories who can lead students to transform ideas into reality. In this study, maker teachers include: In normal universities, normal students who will be engaged in maker education in the future, such as: normal students (quasi maker teachers) in information technology education, stem education, educational technology and other majors; front-line teachers (maker teachers) who have been engaged in maker education in basic education.

\section{B. Coordinated development}

It is the best way to coordinate two or more different resources or individuals to achieve a winwin result[5]. The coordinated development in this study means that local colleges and universities rely on primary schools to improve the teaching ability of normal students, at the same time basic education relies on local colleges and universities to improve the professional level of maker teachers in basic education.

$\left\{\begin{array}{c}\begin{array}{c}\text { University Instructors } \\ \text { (reduce teaching pressure) }\end{array} \\ \begin{array}{c}\text { Colleges and Universities line maker teacher } \\ \text { collegery maker normal }\end{array} \\ \text { (improve the level of specialization) }\end{array}\right.$

\section{Fig. 1. Collaborative development diagram.}

\section{Final Submission}

After your paper is accepted, you will be asked to upload final DOC file. Also upload a file with complete contact information for all authors. Include full mailing addresses, telephone numbers, fax numbers, and e-mail addresses. Designate the author who submitted the manuscript as the "corresponding author." This is the only author to whom proofs of the paper will be sent. You will have the option to designate your article as "open access" in perpetuity if you agree to pay the IJEMR open access fee.

\section{RESEARCH STATUS}

\section{A. Research status abroad}

A series of related teacher training modes have been established in foreign countries to promote teachers'professional knowledge, professional quality and professional ability.In the 1980s, the United States formulated the training mode of teachers' development school (PDS), which proposed that the teachers' education professionals should be trained by the cooperation of middle and higher normal schools and primary and secondary schools. In the 1990s, the UK developed a talent training model of partnership[6].It can be seen that foreign countries have long recognized the importance of "collaborative development", encouraged the teacher training mode of "complementary advantages, winwin cooperation", and fully reflected the concept of collaborative development in the training mode of maker teachers.

\section{B. Domestic research status}

Educational practice mode: Normal colleges and universities in China have been carrying out educational practice for the graduating normal 
students in the fourth year of undergraduate course, aiming to combine theoretical knowledge with practical experience, improve teaching level, and provide high-quality teachers for primary and secondary schools. The operation mechanism of the model is as follows: The normal university unifies with the local primary and secondary schools to regard it as the practice school. The normal students go to each school to practice as the teaching assistant of an on-the-job teacher during the fourth grade of the undergraduate course, and finally the on-the-job teachers guide and evaluate the practice. However, there are some problems in the mode of educational practice. For example, some primary and secondary school teachers do not want normal students to affect their teaching progress and do not allow normal students to really enter the classroom [7], there is no teaching guidance for normal students; There are still some normal students who explain the situation to the basic education school teachers, because of their own reasons for postgraduate entrance examination and employment, there is no internship at all. This kind of educational practice can not achieve the expected effect.

"Taking post practice" mode[8]: In order to promote the integration of theoretical knowledge and practical skills of normal students, China has carried out a post practice mode for normal students. Different from the general education practice mode, the post practice realizes that the platform is completely handed over to normal students. Through a stage of practice, the teaching level of normal students will be improved to a certain extent. However, there are some disadvantages in this model. For example: generally, the places where internships provided are relatively poor. The schools that need supporting education are also short of teachers, especially the young teachers with high education, which there will be such a problem: no guidance. Usually, the school leaders who need to support teaching bring the students on post to the class he wants to teach in the future, and give the class to the normal students completely. The normal students only have their own teaching class, and they can only rely on themselves to carry out teaching exploration and try in the teaching process. Because they are new teachers after all, there is no professional and experienced teacher guidance, then the normal students will inevitably have some detours on the way of teaching growth, and the space for their own growth is also very limited.

"Double tutor system" mode: In recent years, normal colleges and universities have reformed the training mode of normal students. A normal student is equipped with a college instructor and a basic education on-the-job instructor. The ideal model of "double tutor system" will break the limitation of the former model. The tutors can not only give theoretical and academic guidance to normal students, but also teach some teaching experience. The ideal is always beautiful, but the reality is not so. In fact, the "Double Tutorial System" is merely oral, and has not really been realized. Because there is no substantive plan between the teachers of colleges and universities and basic education schools, and they do not really communicate, the traditional training mode of "double mentors" is difficult to give full play to its due effect[9].

\section{MODE CONSTRUCTION}

The main driver of maker education is maker teachers. One of the main reasons why maker education can't play its due role is the lack of teachers. Therefore, it is necessary to build a training model of maker teachers in line with the new era. In 2014, the Ministry of Education issued the opinions on the implementation of the excellent teacher training plan, which advocates the establishment of a new mechanism for universities, local governments and primary and secondary schools to jointly train teachers[10]. The current situation of normal school students is "emphasizing theory but not practice" and the types of maker resources are rich; The current situation of maker teachers in basic education is "more experience but less specialization" and the form of maker activities is single due to capital constraints. Hence, Taking the two as the cooperative development objects and learning from each other's strengths and complementing each other's weaknesses, these win-win results can not only improve the quality of maker teachers, but also promote the further development of maker education. The training mode of maker teachers of local colleges and universities and basic education constructed under the concept of coordinated development is shown in Figure 1: 


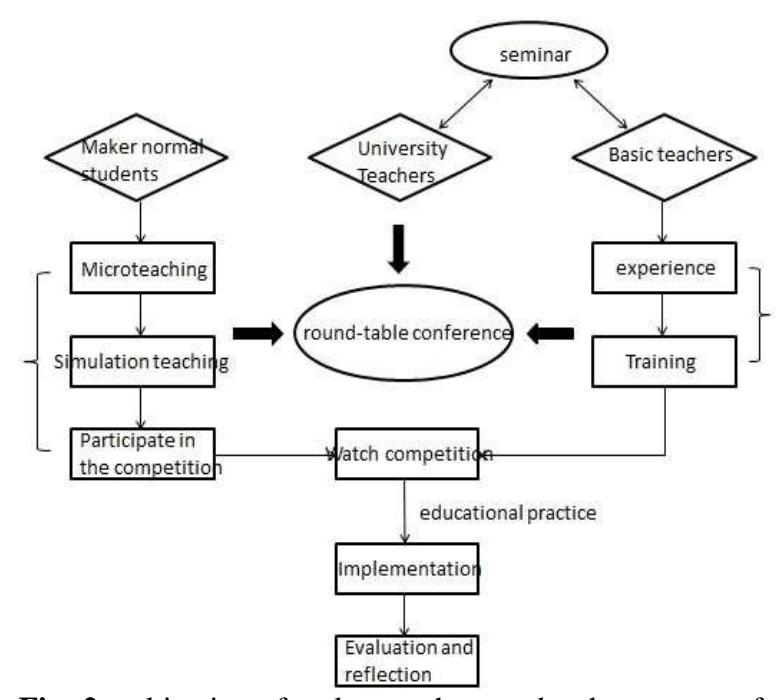

Fig. 2. cultivation of maker teachers under the concept of coordinated development.

The construction of learning environment is an important factor for the successful implementation of the training model of maker teachers. Based on the training model of maker teachers in this study, the maker laboratories in colleges and universities need to meet at least four training processes: micro teaching, simulation teaching, training lectures and round tables. Maker education emphasizes the cultivation of innovation ability, hands-on ability and cooperation ability. Maker laboratory should provide an independent learning environment that can realize cooperative learning and find learning resources at any time[13]. In order to better implement the training model of maker teachers in this study, this paper designs a maker laboratory.

Area A: interactive electronic whiteboard, presenting teaching contents for learners. Area B: teacher computer. Area C: A full range of books and other learning materials. In addition to maker books, it should also include science, mathematics, physics, chemistry, biology and other related books. To create an environment for learners to learn independently and actively obtain all kinds of learning resources. Area D: Students' study desk, usually with 3-4 people as a group, which can rise and fall the computer through the control button. When learning the knowledge of software and program, the computer can be raised, and the computer can be lowered during hands-on practice and assembly. Area E: Various maker resources, such as 3D printing. Area F: Put tables and chairs in a circle, which is a platform for communication, exchange and research between university teachers, normal university students and maker teachers of basic education. Area G: Experience for on-the-job maker teachers and visit the exhibition of outstanding cutting-edge maker products. It should be noted that in order to better point out the problems existing in the teaching of maker normal students, it is necessary to monitor and manage their teaching process[14]. Therefore, it is necessary to have HD cameras.

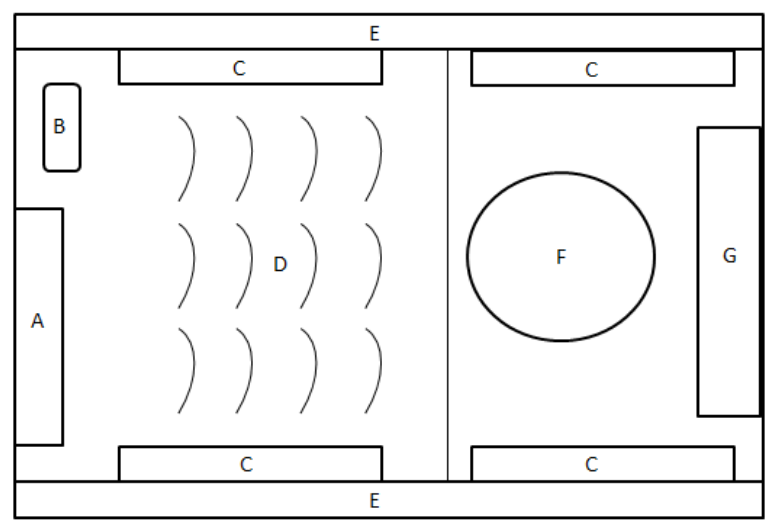

Fig. 3. Design drawing of maker Laboratory.

\section{A. University tutor}

The purpose of building the training model of maker teachers under the concept of coordinated development of local universities and basic education is to cultivate more high-quality maker teachers to provide excellent maker teachers for basic education and to promote the better development of maker education. As a reserve force and an important force of maker teachers, maker normal students have been concerned. In the past training system, the college tutor as the only trainer makes the training plan. In this training mode, the trainers of maker normal students are both college tutors and on-the-job maker teachers. Since their common goal is to cultivate high-quality maker normal students, in order to avoid disputes in the next training process, they need to discuss and formulate training programs together before training. The maker instructors in normal colleges and universities can communicate with the on-the-job maker teachers in basic education in the form of seminars to jointly formulate the training program for maker normal students. Only when the training objectives of "two mentors" are consistent, can the next training be carried out smoothly.

College instructors have rich educational and teaching theories, high scientific research ability, solid theoretical basis and the ability to set up corresponding courses of maker. In the second year of normal college students, they can set up corresponding courses of maker that meet the training objectives, such as machine-based education. Through the study of this course, the students of maker normal school can understand the concept of maker and preliminarily master the corresponding theoretical knowledge and teaching methods. In addition to teaching undergraduate courses, university instructors need to do a lot of scientific 
research and their energy is limited. Secondly, college teachers are faced with undergraduates, they have left the stage of basic education and do not know the ability and level of middle school students. Therefore, in the practical teaching process, it is not enough to only guide the college teachers, which needs the participation and help of the in-service teachers of basic education. In this way, it can not only reduce the burden of the college teachers, but also help the maker normal students to improve their teaching skills more practically and practically.

In general, university instructors will apply for projects, get project funds and use project funds to build maker laboratories. Therefore, compared with basic education, the types of maker resources in university maker laboratories are richer and more advanced. University laboratory can not only provide a maker platform for normal students, but also provide a rich maker experience platform for inservice teachers of basic education. College instructors can regularly organize and carry out maker experience activities, giving training and lectures to in-service teachers of basic education, helping in-service maker teachers to understand advanced and rich types of makers, broadening their horizons, and keep pace with the times.

In the whole process of training mode implementation, real-time communication is always required. In every training link, the college guidance teachers should communicate with the teachers in service in the form of round table or seminar, to understand the latest learning and teaching situation of normal students, timely urge the normal students who fail to meet the requirements of training objectives, and appropriately adjust the training program according to the specific situation. In the evaluation of normal students, we should pay more attention to the process evaluation, with qualitative evaluation as the main and quantitative evaluation as the auxiliary.

\section{B. Maker normal students}

After the normal students learn the theoretical knowledge, they should carry out microteaching training during the third grade of the undergraduate course. Microteaching is a small-scale teaching site.There are blackboards, computers, podiums and cameras in front of the microteaching room. Students' desks and chairs are placed in the middle of the classroom. Multi angle conversion cameras are hung on the back wall of the classroom, which is convenient for recording the process of students' lectures. On the one hand, students can download their own video, through the process of watching their own video after class to find their own problems and deficiencies, such as some irregular gestures, actions and correct their shortcomings in the following exercises. "Double tutors" and normal students evaluate the performance of this student through round table meeting and correct the problems in time for normal students to correct. However, a single microtraining is not enough, because in the process of microtraining, there are no real learners under the platform to listen to and interact with each other, and the teachers who practice just conduct according to their own teaching plan. In the real teaching process, there must be interaction between learners and teachers. Since teaching activity is an interactive process, there must be a lot of unpredictability, which requires teachers to have the ability to adapt to the circumstances, flexibly use teaching methods, and deal with various emergencies. Simulation teaching can provide a good platform for normal students to realize teaching interaction, hence, before the normal students arrive at the practice school, the college guidance teachers can communicate with the basic on-the-job maker teachers to carry out simulation teaching in the maker Laboratory of the University.Maker teachers of basic education choose some students to participate in the theme activities of colleges and universities. In the simulation teaching part of this study, the students from the first grade class of the local junior high school were invited to participate in the two-day robot intelligent car ultrasonic obstacle avoidance and intelligent car remote control obstacle avoidance activities on Saturday and Sunday, Normal students as lecturers and teaching assistants. In the process of simulation teaching, basic education instructors and university instructors will listen in. After the activity, through the round table to comment on the performance of normal students. Through the simulation teaching link, it can improve the normal students' ability of organizing education and teaching activities, as well as the ability of teaching site response.

An excellent maker teacher should be a maker himself. He should have the ability of innovation, hands-on practice and the spirit of keeping pace with the times. In order to improve their maker literacy, they should participate in some maker competitions, such as: enrolling university students robot competition. Normal students have no experience of maker competition, and may have no way to start, which requires "double mentors" for technical guidance and experience sharing. In this study, normal students participated in the robot competition of provincial colleges and universities. In the threemonth preparation, normal students learned more about the function and function of each part, improved their practical ability, opened up a sense of space and divergent thinking through the process of building and assembling robots by themselves, so that their professional knowledge and maker literacy has been greatly improved. At the scene of the 
competition, we can get in touch with the works brought by different college teams, observe the works of others, find out what we can learn from the works, get some inspiration, understand the latest technology frontier, and make our vision wider. Through the experience of preparation and competition, maker teachers can lead their own teams to participate in maker competition after they are engaged in maker education in the future.

\section{In service maker teacher}

At present, compared with normal students, although maker teachers in basic education have rich teaching experience, most of the primary and secondary schools are made up of science teachers and information technology teachers, Their professional level is relatively low. There are few normal students who have really learned the maker education course, and the number of maker teachers is relatively small. Because of the limitation of funds, most schools are equipped with maker resources, but the types and forms of maker are relatively single, so they can not access to rich maker resources. Many teachers' theories and knowledge are still in the "old knowledge" that they learned in colleges and universities, lacking the ability of innovative teaching. Some teachers can't start even though they want to contact the latest technology and learn the latest theory[11]. In the mode of collaborative development and training, colleges and universities provide a new learning platform for in-service teachers of basic education. A series of maker training activities and lectures are organized by the university tutor and cooperated by maker normal students. In the activities and lectures, the university tutor conducts professional training for the on-thejob teachers, and the normal students act as assistant teachers, so that the on-the-job maker teachers can improve their theoretical research and professional level through the process of observing, experiencing, learning and mastering the most cutting-edge maker resources. To ensure that professional knowledge keeps pace with the times and broaden their new vision of maker education.

From the perspective of maker normal students, they have already possessed the preliminary practical teaching ability through the preliminary micro training and simulation teaching links. From the perspective of in-service maker teachers, their professional level and theoretical research level have been improved to a certain extent after they have learned more and updated maker resources. Maker normal students and maker teachers of basic education can formulate maker courses suitable for schools through seminars, round tables and other forms, combining the theoretical basis, the actual situation of the maker education resources of the school and the level of learners. For example robot courses, 3D printing courses. Only when the maker normal students really enter the classroom, can they find problems, solve problems and improve their education and teaching level. Therefore, after designing the maker course suitable for the school, they can take the course to the basic school for teaching, which is the so-called education practice. Considering the characteristics of maker course different from other traditional courses, it is more suitable to be carried out in the form of maker community. In the whole course of educational practice, the on-the-job maker teachers participate in the maker course, which they can understand the teaching situation of the maker normal students and guide the existing problems after class. After the practice, the practice results of maker normal students are evaluated jointly by maker teachers of basic education and college guidance teachers. The evaluation should adopt multi-element assessment [12], which is a process evaluation in the whole process of this stage. Students can reflect and summarize according to the evaluation results, that is, participate in the practice reflection and summary, which is a continuous cycle process.

\section{Conclusion}

From the perspective of normal students in Colleges and universities, the training model of maker teachers under the concept of coordinated development of local colleges and basic education constructed in this paper can make up for the shortcomings existing in the previous training model of teachers, not only provide full internship opportunities for normal students, but also provide them with teaching guidance, so that normal students can fully integrate theory and practice and improve their own teaching level. From the perspective of inservice teachers in basic education, it provides teachers with rich theoretical knowledge, the latest professional maker platform, and improves teachers' professional quality. From the point of view of university teachers, it reduces the teaching pressure, improves the teaching skills and professional level of students, providing a platform for front-line teachers to learn new knowledge. In this way, not only more high-quality maker teachers for basic education, but also better promote the development of maker education.

\section{ACKNOWLEDGMENT}

This paper is the stage research achievement of the general subject of higher education scientific research of Jilin Institute of higher education in 2019, "Research on the cultivation of maker teachers under the concept of coordinated development of local universities and basic education" (subject approval No: JGJX2019D37). 


\section{REFERENCES}

[1] Yuanjun Jin ( 2014 ) . Research and Practice on the development of school-based teaching materials under the background of maker. A Graduation Thesis of Shanghai Normal University.

[2] Lixin Zhang ( 2014 ). Extension and expansion of maker Education- On the integration of freeze frame animation and Curriculum, ( 11$): 9$.

[3] Hanlin $\mathrm{Hu}$ ( 2019 ). Primary school maker teachers are facing difficulties and solutions.Teaching and management, (2): 4-5.

[4] BoChang Zhong, Lu Zhang, Yanxia Wang(2018).The present and future of maker education. People's education, (5): 63 .

[5] Baidu Encyclopedia. Https://baike.so.com/doc/92431149576463.html, 2017.

[6] lingbing Kong(2015). On the cooperative training mechanism between normal universities and primary and secondary schools in pre service Teacher Education. Heilongjiang Higher Education Research, (2): 98.

[7] Shuzhen Huang(2009). Research on the practice of educational practice in the interaction of professional development of pre service and post service teachers. Educational theory and practice, (29): 42-43.

[8] Ying Cao(2016). Exploration and analysis on the reform of post-taking practice under the mode of innovator education in higher vocational colleges. Cultural and educational materials, (13) : 94

[9] Xiaofeng Wang(2019).On the construction of teaching skill training system of double-tutorial system for normal school students. Science, education and culture, (11): 69 .

[10] Jianzhang Yan, Jing Li(2018). Analysis on the formation mechanism of the new mechanism of collaborative training of teachers between universities, local governments and primary and secondary schools - based on the perspective of symbiosis theory. Contemporary education science, (7): 49.

[11] Hui Yang ( 2017 ) .On the professional development of maker teachers. Scientific consultation, (15): 1 .

[12] Tongqiang Dong, Xiufeng $\mathrm{Ma}$ (2018). Construction and application of maker teacher participatory training mode in primary and secondary schools. Modern education technology, (28): 115-116.

[13] Jian Yin ( 2019 ) . Research on the cultivation of innovative talents in Local Applied Colleges and Universities Based on maker's laboratory. Education modernization, (72): 4-5.

[14] Kai Nie ( 2019 ). On the reconstruction imagination of the construction of the science and engineering maker laboratory in Colleges and universities. Science and technology and innovation, (21): 8-9.

[15] Hongye Chen,Xian $\mathrm{Si}(2019)$.Research on the training model of innovative practical ability of educational technology students based on the education of creative. Contemporary Educational Practice and teaching research,(4):171-172.

[16] Wenwen $\mathrm{Tu}(2019)$. Reflections on the construction of innovative talents training mode in colleges and universities by creationist education. Curriculum Education Research,(10):59. 